\title{
WRF-Chem modeling of sulfur dioxide emissions from the 2008 Kasatochi Volcano
}

\author{
Sean D. Egan ${ }^{1 *}$, Martin Stuefer ${ }^{1}$, Peter W. Webley ${ }^{1}$, \\ Catherine F. Cahill ${ }^{1}$, Jonathan Dean ${ }^{1}$ \\ 1 University of Alaska Fairbanks, Geophysical Institute \\ *sdegan@alaska.edu
}

\begin{abstract}
We simulate the dispersion and chemical evolution of the sulfur dioxide $\left(\mathrm{SO}_{2}\right)$ plume following the eruption of Kasatochi Volcano in Alaska, USA, on August 7th, 2008 with the Weather Research Forecasting with Chemistry (WRF-Chem) model. The model was initialized with the observed three distinct plumes, which were characterized by a total estimated $\mathrm{SO}_{2}$ mass of 0.5 to $2.7 \mathrm{Tg}$. WRF-Chem modeled output was compared to remote sensing retrievals from the Ozone Monitoring Instrument (OMI), and the modeled plumes agreed well in shape and location with the OMI retrievals. The calculated $\mathrm{SO}_{2}$ column densities showed comparable Dobson Unit values with higher densities especially in the center of the distal plume over northern Canada. We concluded from our analysis that WRF-Chem derived a 9.1-day lifetime of the $\mathrm{SO}_{2}$ when initialized with a $12 \mathrm{~km}$ eruption height. Sensitivity tests with varying eruption plume heights revealed significantly increased lifetimes of $\mathrm{SO}_{2}$ up to 17.1 days for higher plumes.
\end{abstract}

\section{INTRODUCTION}

$\mathrm{K}$ asatochi volcano $\left[52.169^{\circ} \mathrm{N}, 175.511^{\circ} \mathrm{W}\right]$ is a small $(2.7 \times 3.3 \mathrm{~km}, 314 \mathrm{~m}$ above sea level, a.s.l.), uninhabited stratovolcano in the Aleutian Arc of Alaska (Scott, Nye, Waythomas, \& Neal, 2010). On August 2nd, 2008 US Fish and Wildlife biologists reported small tremors and a sulfur odor while on assignment (Waythomas et al., 2010). They were evacuated prior to a M5.8 earthquake on August $7^{\text {th }}, 2008$ at 2:00 pm AKDT (22:00 UTC), detected by instruments from the Great Sitkin seismic Network. Infrared satellite retrievals from the Advanced Very High Resolution Radiometer (AVHRR) confirmed the presence of a volcanic plume situated over the volcano's vent during this time (Waythomas et al., 2010).

Two additional eruptions followed at 01:50 UTC and 04:35 UTC (Scott et al., 2010). The ash and $\mathrm{SO}_{2}$ emissions dispersed in a complex pattern due in large part to a low-pressure cyclogenesis situated nearly on top of the volcano (Krotkov, Schoeberl, Morris, Carn, \& Yang, 2010). Coarse ash and fine lapilli deposited quickly while most of the fine ash and $\mathrm{SO}_{2}$ initially dispersed to the southeast (Waythomas et al., 2010). The resulting $\mathrm{SO}_{2}$ plume eventually entered the jet stream and traveled into the continental United States and Canada within a week (Krotkov et al., 2010).

The Kasatochi eruption is unique for various reasons. It resulted in the largest injection of $\mathrm{SO}_{2}$ into the atmosphere since the Mount Hudson eruption in Chile, August 1991. Initial estimates were between 1.20 to $2.7 \mathrm{Tg}$ (Krotkov et al., 2010; Prata, Gangale, Clarisse, \& Karagulian 2010). By using inverse transport modeling, Kristiansen et al. (2010) established a $1.7 \mathrm{Tg}$ 
mass loading. In addition, plume altitudes exceeded the tropopause (maxima near 7 to $12 \mathrm{~km}$ with smaller emissions up to $20 \mathrm{~km}$ ) introducing about $1.0 \mathrm{Tg}$ of $\mathrm{SO}_{2}$ into the stratosphere (Kristiansen et al., 2010).

Modeling $\mathrm{SO}_{2}$ emissions is useful for various reasons. $\mathrm{SO}_{2}$ is often collocated with volcanic ash and thus may be used as a proxy for ash where remote sensing is hindered by ice formation, water or cloud cover. Additionally, WRF-Chem studies of historical volcanic eruptions are motivated to test and provide source data and model parameterization schemes capable of predicting volcanic $\mathrm{SO}_{2}$ and ash eruptions in an operational setting in near real-time. Here, we use the well-defined Kasatochi $\mathrm{SO}_{2}$ eruption to study WRF-Chem's ability to model volcanic $\mathrm{SO}_{2}$ transport and conversion.

\section{BACKGROUND}

Sulfur dioxide emissions from Kasatochi have been modeled previously with particle dispersion models (D'Amours et al., 2010; Kristiansen et al., 2010). Wang and others (2010) studied $\mathrm{SO}_{2}$ dispersion and aerosol formation plume height sensitivity using the Eulerian GEOSChem model by initializing the model domain with time-fitted $\mathrm{SO}_{2}$ column densities from the Ozone Monitoring Instrument (OMI) using the Extended Iterative Spectral Fit (EISF) method. This WRF-Chem study differs from the GEOSChem study in that it does not require plume column densities, only specific eruption source data such as location, height, emission rate and duration. These parameters are included in tabulated Eruption Source Parameters (Mastin et al., 2009), which may be used to initialize WRFChem for operational volcanic ash and $\mathrm{SO}_{2}$ forecasts. Sulfur dioxide converts quickly (on the order of days) to sulfate aerosols. In the stratosphere, where the majority of the Kasatochi $\mathrm{SO}_{2}$ converted to sulfate, the conversion process is dominated by the interaction of $\mathrm{SO}_{2}$ with the hydroxyl radical $(\bullet \mathrm{OH})$. Production of $\bullet \mathrm{OH}$ begins with the generation of excited states of atomic oxygen from ozone and diatomic oxygen via photolysis. The hydroxyl radical oxidizes $\mathrm{SO}_{2}$ in the stratosphere according to Equation 1.

$$
\mathrm{SO}_{2}+\cdot \cdot \mathrm{OH}+\mathrm{M} \rightarrow \mathrm{HOSO}_{2}+\mathrm{M}^{*}
$$

$\mathrm{M}^{*}$ is a third body quencher required to remove excess energy from the reaction. This process was initially proposed to decrease the ambient amount of $\bullet \mathrm{OH}$, and thus a second order rate equation would be needed to model it. However, as mentioned by McKeen, Liu, \& Kiang (1984), there is a cycling of the hydroperoxy radical, $\mathrm{HO}_{2} \bullet$, and $\bullet \mathrm{OH}$ in the presence of nitrogen oxide species, $\mathrm{NO}_{x}$ (McKeen et al., 1984):

$$
\begin{aligned}
& \mathrm{O}_{2}+\mathrm{HOSO}_{2} \rightarrow \cdot \mathrm{HO}_{2}+\mathrm{SO}_{3} \\
& \bullet \mathrm{HO}_{2}+\mathrm{NO} \rightarrow \bullet \mathrm{OH}+\mathrm{NO}_{2}
\end{aligned}
$$

This cycling ensures the regeneration of $\bullet \mathrm{OH}$ concentration. If we assume $[\bullet \mathrm{OH}]$ is constant and $[\mathrm{M}]$ varies only with pressure, we may solve the following differential equation to analytically calculate the change in concentration of $\mathrm{SO}_{2}$ with time:

$$
\begin{aligned}
& \frac{d \mathrm{SO}_{2}}{d t}=-k_{3}\left[\mathrm{SO}_{2}\right][\bullet \mathrm{OH}][\mathrm{M}] \\
& {\left[\mathrm{SO}_{2}\right]_{f}=\left[\mathrm{SO}_{2}\right]_{i} e^{-k_{3, \mathrm{M}}[\bullet \mathrm{OH}] t}}
\end{aligned}
$$

Here, $k_{3}[M]$ is the pseudo first order rate constant based on Equation 3.

Sulfur dioxide and $\bullet \mathrm{OH}$ also interact via aqueous phase reactions. In such reactions, $\bullet \mathrm{OH}$ is produced by dissolved hydrogen peroxide in water, which then reacts with dissolved, aqueous $\mathrm{SO}_{2}$.

III. METHODS 
The application of WRF-Chem for simulating the transport and effects of volcanic emissions within the atmosphere has been described in (Stuefer et al., 2013). Importantly, WRF-Chem has been proposed as an operational tool for volcanic emissions modeling. Here, we test the feasibility of using WRF-Chem to capture $\mathrm{SO}_{2}$ emissions using the well-studied 2008 Kasatochi eruption.

The choice of eruption initialization parameters greatly impacts the ability of the model to predict volcanic ash and $\mathrm{SO}_{2}$ transport (Mastin et al., 2009; Webley, Stunder, \& Dean, 2009). Table 1 lists the domain initialization parameters used in this study and Table 2 provides the initialization parameters for the eruption. We utilized the Global Forecast System (GFS) Final Reanalysis (FNL) datasets as base meteorological fields (NOAA, 2014).

WRF-Chem may use either default values for Eruption Source Parameters (ESP) or if available, source data from plume observations. Karagulian and others (2010) discovered a minimum of $1.7 \mathrm{Tg} \mathrm{SO}_{2}$ from the Kasatochi eruption using remote sensing data from the Infrared Atmospheric Sounding Interferometer (IASI). Kristiansen and others (2010) utilized inverse transport modeling to establish a similar mass of $1.7 \mathrm{Tg}$ based on measurements from UV, IR and Lidar data. In a recent GEOS-Chem study by Wang et al. (2013) a value of $2.0 \mathrm{Tg} \mathrm{SO} \mathrm{SO}_{2}$ was used. Herein, we initialized WRF-Chem with a total of $1.7 \mathrm{Tg}$ of $\mathrm{SO}_{2}$. This mass was gradually added to the model using a constant eruption rate of $23,600 \mathrm{kgs}^{-1}$ over the course of the three eruptions, using eruption durations and times based on Waythomas et al. (2010) (compare Table.

WRF-Chem initializes, by default, volcanic ash and $\mathrm{SO}_{2}$ plumes as an umbrella shape with $75 \%$ of erupted mass in the plume surrounding the specified plume height and $25 \%$ of the mass linearly detrained underneath (Stuefer et al., 2013). For the eruption plume height, the ESP implemented within the WRF-Chem preprocessor as a default includes a height of $11 \mathrm{~km}$ for Kasatochi. However, in accordance with Kristiansen et al. (2010), we chose $12 \mathrm{~km}$ a.s.1 $\pm 4 \mathrm{~km}$ for this study in order to test the sensitivity of the model to its plume height source. For the example of our mean plume height of $12 \mathrm{~km}$ a.s.l, the umbrella will include $75 \%$ of the mass between 9 - $13 \mathrm{~km}$ a.s.l (peaking at $12 \mathrm{~km}$ a.s.l) and $25 \%$ below $9 \mathrm{~km}$, linearly decreasing with height (Stuefer et al, 2013).

Table 1: Domain parameters for WRF-Chem

\begin{tabular}{|l|l|}
\hline Domain Size & $600 \times 400$ \\
$\mathrm{dx}, \mathrm{dy}$ & $15 \mathrm{~km} \times 15 \mathrm{~km}$ \\
Vertical levels & 40, terrain following \\
Model Height & $2,000 \mathrm{~Pa}$ \\
Projection & Lambert-Conformal \\
Center Lat/Lon & $50^{\circ} \mathrm{N},-120^{\circ} \mathrm{W}$ \\
\hline
\end{tabular}

Kasatochi erupted over half of the $\mathrm{SO}_{2}$ into the stratosphere. Therefore, it is important to capture the gas-phase chemistry behind stratospheric $\mathrm{SO}_{2}$ oxidation shown in Equation 1. The model simulations utilized the Second Generation Regional Acid Deposition Model Mechanism (RADM2) for gas and aqueous phase reactions. The RADM2 model includes the oxidation of $\mathrm{SO}_{2}$ by $\cdot \mathrm{OH}$ as depicted in Equation 1 using the first order kinetics in Equations 4 and 5 (Stockwell et al., 1990) as well as the treatment of the $\mathrm{NO}_{x}$ species in Equations 2 and 3. Gaseous precursors, such as $\mathrm{NO}$ and $\bullet \mathrm{OH}$, were loaded into the model using the Prep-ChemSource 1.4 preprocessor (Freitas et al., 2011). As mentioned, $\mathrm{SO}_{2}$ also converts via aqueous phase chemistry with $\bullet \mathrm{OH}$. This scheme is also parameterized within WRF-Chem RADM2. 
Table 2: Eruption times and durations

\begin{tabular}{|l|l|l|}
\hline $\begin{array}{l}\text { Eruption Date, } \\
\text { Time }\end{array}$ & $\begin{array}{l}\text { Eruption Du- } \\
\text { ration }\end{array}$ & $\begin{array}{l}\text { Eruption } \\
\text { Rate }\end{array}$ \\
\hline 8/7 22:00 UTC & 60 minutes & $23600 \mathrm{~kg} / \mathrm{s}$ \\
8/8 01:50 UTC & 30 minutes & $23600 \mathrm{~kg} / \mathrm{s}$ \\
8/8 04:35 UTC & 30 minutes & $23600 \mathrm{~kg} / \mathrm{s}$ \\
\hline
\end{tabular}

Global ozone and other trace gases, such as $\mathrm{SO}_{2}$, are detected by the Ozone Monitoring Instrument (OMI), a nadir viewing, ultraviolet (UV)/visible spectrometer aboard the National Aeronautical \& Space Administration's (NASA) Earth Observing System's (EOS) Aura satellite. OMI covers a spectral range of 264-504 $\mathrm{nm}$, allowing measurements of ultraviolet and visible $\mathrm{SO}_{2}$ signals. It provides global coverage once per day with a nadir pixel size of $13 \times 24$ $\mathrm{km}^{2}$ and swath width of $2,600 \mathrm{~km}$ and has been used in previous research studies for volcanic emissions analysis (Kristiansen et al., 2010; Krotkov et al., 2010; Lopez et al., 2013; Wang et al., 2013).

For spatial analysis, we utilized NASA's Level $2 \mathrm{SO}_{2}$ product, ColumnAmount $\mathrm{SO}_{2} \mathrm{STL}_{\mathrm{ST}}$ (from here on STL). Column densities of $\mathrm{SO}_{2}$ in Dobson Units (DU) for this product are shown in Figure 1. Since the STL derived data may underestimate the total amount of $\mathrm{SO}_{2}$ in plume areas of high concentration, we used values from Krotkov et al. (2010) based on the Extended Iterative Spectral Fit (EISF) method for mass analysis. Applications of this method to Kasatochi $\mathrm{SO}_{2}$ suggest that it may capture additional $\mathrm{SO}_{2}$ that other algorithms might miss (Krotkov et al., 2010; Yang et al., 2010).

\section{RESULTS}

Figure 1 shows the dispersion of the plume as modeled by WRF-Chem and derived by the OMI STL product. The model captured the plume's interaction with the meteorology well, as it dispersed over the North American continent. Figure 2 shows a brief spatial analysis along two transects (105W and $145 \mathrm{~W})$ marked in red. Plume $\mathrm{SO}_{2}$ column densities were generally collocated with OMI here, however the normalized masses peaked in different areas. To compare the change in mass in the domain, a linear correlation plot was constructed and presented in Figure 3. We saw a high degree of correlation $\left(>0.9 \mathrm{r}^{2}\right)$ for all plume height test cases between the change in WRF-Chem predicted $\mathrm{SO}_{2}$ mass and those observed by OMI.

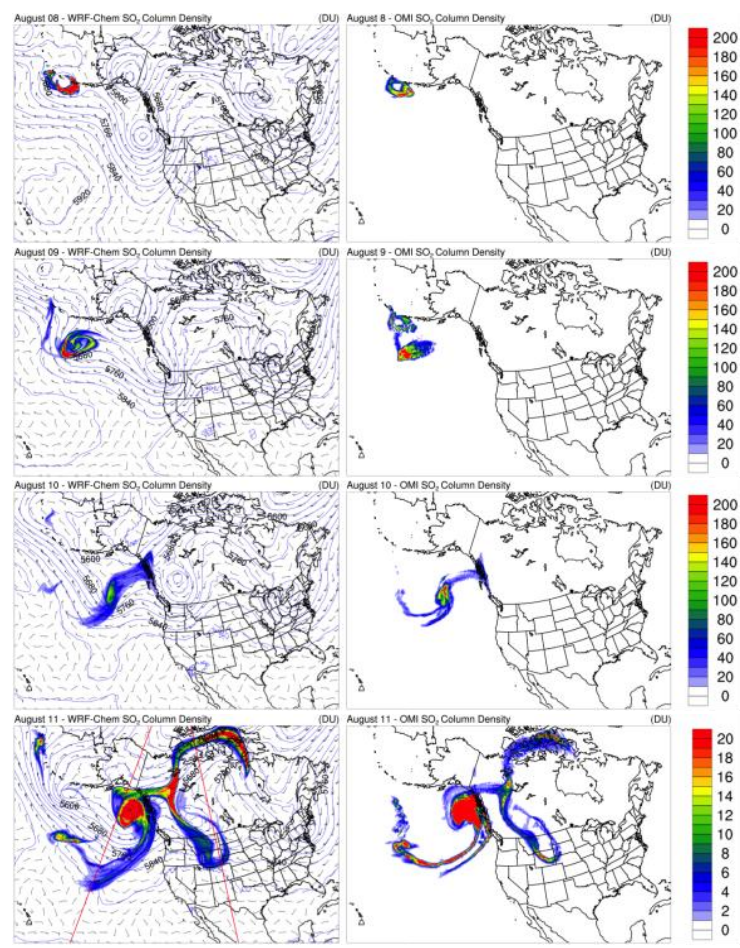

Figure 1: Dispersion of the Kasatochi $\mathrm{SO}_{2}$ plume as modeled by WRF-Chem (left) and calculated by the OMI STL product (right). The transects used for spatial analysis are shown in red on the August $11^{\text {th }}$ plot. Geopotential height and wind vectors are plotted on WRF-Chem plots.

A lifetime of $\mathrm{SO}_{2}$ was established using linear regression analysis; the lifetimes significantly 
varied with height. The $12 \mathrm{~km}$ eruption height yielded a 9.1 days lifetime $\left(\mathrm{r}^{2}=0.74\right)$ while the $8 \mathrm{~km}$ and $16 \mathrm{~km}$ plumes resulted in longer lifetimes of 10.6 and 17.1 days $\left(r_{2}=0.72,0.68\right)$, respectively.

\section{DisCUSSION}

WRF-Chem generally predicted a more disperse plume than was observed by OMI. In addition, there is a higher mass bias in the model results. This is markedly different from the work of Wang et al. (2010) where GOES-Chem produced a low mass bias. In addition, the mass located in the distal plume trended higher than that in the proximal. This is likely a direct result of the chosen ESP used for the modeled case as this varied with the plume height.

The rate of $\mathrm{SO}_{2}$ conversion agreed well with literature values. We used values from Krotkov et al. (2010) using the EISF method and from Kristiansen et al., (2010) to test WRF-Chem output. In Figure 3 we see that all three initialized eruption heights produced $\mathrm{r}^{2}$ values above 0.9 . As mentioned, a range of values was produced for the lifetime using linear regression analysis. The $12 \mathrm{~km}$ eruption produced the shortest lifetime, being about 9 days. This dependence of lifetime on plume height is most likely a direct result of different chemistry at the various levels of the atmosphere. The $12 \mathrm{~km}$ eruption included $\mathrm{SO}_{2}$ mass located mostly in the stratosphere where conversion based on Equation 1 dominated, yet also included enough $\mathrm{SO}_{2}$ in the troposphere where aqueous phase and heterogeneous chemistry can also occur.

WRF-Chem captured the dynamics and mass changes of the Kasatochi plume according to these results. It is, therefore, a robust candidate for volcanic emissions modeling, especially in the operational setting where multiple unknowns such as a specific plume height are present.
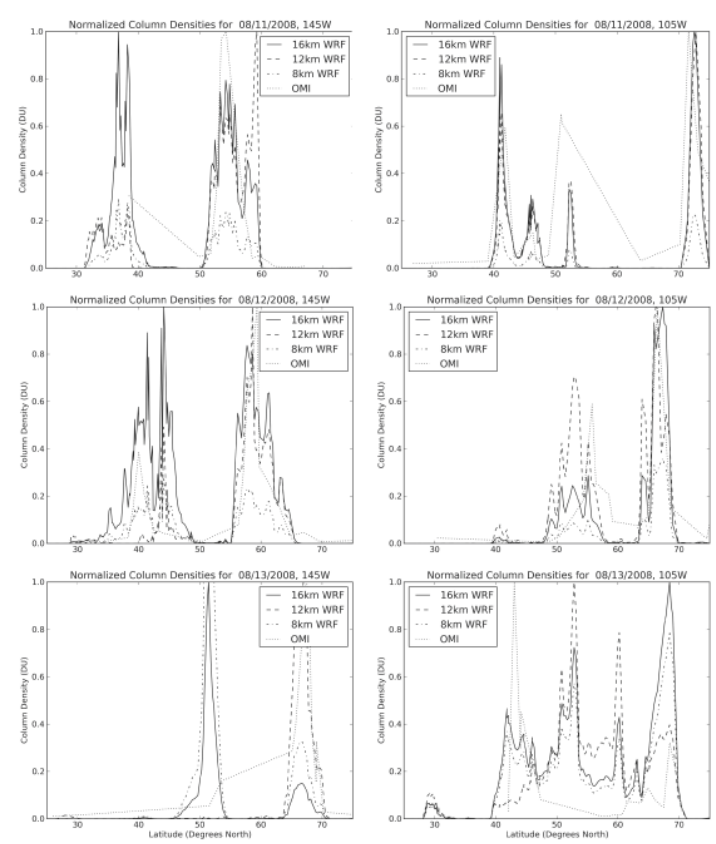

Figure 2: Spatial comparisons of $\mathrm{SO}_{2}$ column densities from WRF-Chem using 8, 12 and $16 \mathrm{~km}$ initialized plume heights and from the OMI STL product.

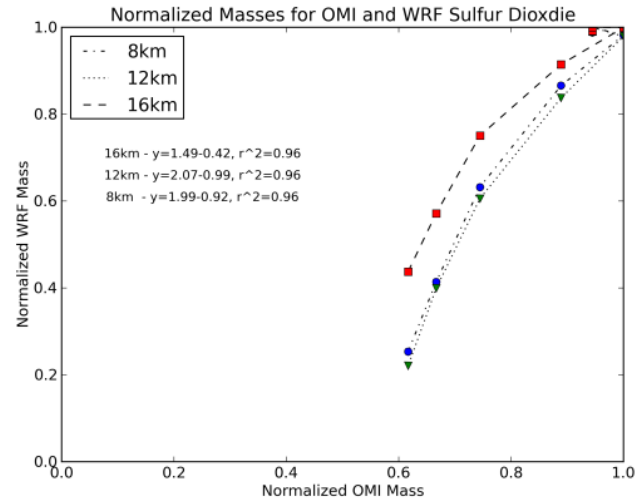

Figure 3: Correlation between WRF-Chem (y-axis) and literature $\mathrm{OMI}$ ( $x$ axis) $\mathrm{SO}_{2}$ domain masses for 8, 12 and $16 \mathrm{~km}$ plume heights.

\section{REFERENCES}

[D'Amours et al., 2010] D'Amours, R., Malo, A., Servranckx, R., Bensimon, D., Trudel, S., \& Gauthier-Bilodeau, J.-P. (2010). Application of the atmospheric Lagrangian particle dispersion model MLDP0 to the 2008 eruptions of Okmok 
and Kasatochi volcanoes. Journal of Geophysical Research: Atmospheres, 115(D2), D00L11. [Freitas et al. 2011] Freitas, S. R., Longo, K. M., Alonso, M. F., Pirre, M., Marecal, V., Grell, G., Sánchez Gácita, M. (2011). PREP-CHEM-SRC 1.0: a preprocessor of trace gas and aerosol emission fields for regional and global atmospheric chemistry models. Geoscientific Model Development, 4(2), 419-433.

[Karagulian et al., 2010] Karagulian, F., Clarisse, L., Clerbaux, C., Prata, A. J., Hurtmans, D., \& Coheur, P. F. (2010). Detection of volcanic $\mathrm{SO}_{2}$, ash, and $\mathrm{H} 2 \mathrm{SO} 4$ using the Infrared Atmospheric Sounding Interferometer (IASI). Journal of Geophysical Research, 115(D2), D00L02.

[Kristiansen et al., 2010] Kristiansen, N. I., et al. (2010). Remote sensing and inverse transport modeling of the Kasatochi eruption sulfur dioxide cloud. Journal of Geophysical Research, 115(D2), D00L16.

[Krotkov et al., 2010] Krotkov, N. A., et al. (2010). Dispersion and lifetime of the $\mathrm{SO}_{2}$ cloud from the August 2008 Kasatochi eruption. Journal of Geophysical Research, 115(D2), D00L20.

[Lopez et al., 2013] Lopez, T., Carn, S., Werner, C., Fee, D., Kelly, P., Doukas, M., Schneider, D. (2013). Evaluation of Redoubt Volcano's sulfur dioxide emissions by the Ozone Monitoring Instrument. Journal of Volcanology and Geothermal Research, 259, 290-307.

[Mastin et al., 2009] Mastin, L. G., et al. (2009). A multidisciplinary effort to assign realistic source parameters to models of volcanic ashcloud transport and dispersion during eruptions. Journal of Volcanology and Geothermal Research, 186(1-2), 10-21.

[McKeen et al., 1984] McKeen, S. A., et al. (1984). On the chemistry of stratospheric $\mathrm{SO}_{2}$ from volcanic eruptions. Journal of Geophysical Research, 89(D3), 4873-4881.

[NOAA, 2014] NOAA. (2014, June 18). National Centers for Environmental Prediction Global Forecast System (Final) global gridded analysis archive - 2000 to Present. Retrieved June 18, 2014, from rda.ucar.edu/datasets/ds083.2
[Prata et al, 2010] Prata, A. J., et al. (2010). Ash and sulfur dioxide in the 2008 eruptions of Okmok and Kasatochi: Insights from high spectral resolution satellite measurements. Journal of Geophysical Research, 115, D00L18.

[Scott et al., 2010] Scott, W. E., et al. (2010). August 2008 eruption of Kasatochi volcano, Aleutian Islands, Alaska - Resetting an island landscape. Arctic, Antarctic and Alpine Res.,42(3),250-259.

[Stockwell et al., 1990] Stockwell, W. R., et al. (1990). The second generation regional acid deposition model chemical mechanism for regional air quality modeling. Journal of Geophysical Research, 95(D10), 16343-16,367.

[Stuefer et al., 2013] Stuefer, M., et al. (2013). Inclusion of ash and $\mathrm{SO}_{2}$ emissions from volcanic eruptions in WRF-Chem: development and some applications. Geosci. Model Dev., 6(2), 457-468.

[Wang et al., 2013] Wang, J., et al. (2013). Modeling of 2008 Kasatochi Volcanic Sulfate Direct Radiative Forcing: Assimilation of $\mathrm{OMI} \mathrm{SO}_{2}$ Plume Height Data and Comparison with MODIS and CALIOP Observations. Atmospheric Chemistry and Physics, 13, 1895-1912.

[Waythomas et al., 2010] Waythomas, C. F., et al. (2010). The 7-8 August 2008 eruption of Kasatochi Volcano, central Aleutian Islands, Alaska. Journal of Geophysical Research: Solid Earth (1978-2012), 115(B12).

[Webley et al., 2009] Webley, P. W., et al.,. (2009). Preliminary sensitivity study of eruption source parameters for operational volcanic ash cloud transport and dispersion models - A case study of the August 1992 eruption of the Crater Peak vent, Mount Spurr, Alaska. Journal of Volcanology and Geothermal Research, 186(1-2), 108-119.

[Yang et al., 2010] Yang, K., et al. (2010). Direct retrieval of sulfur dioxide amount and altitude from spaceborne hyperspectral UV measurements: Theory and application. Journal of Geophysical Research: Atmospheres, 115(D2). 